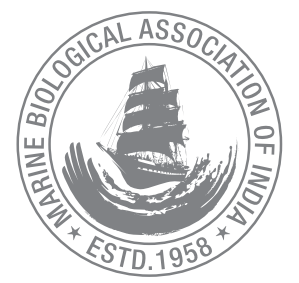

\title{
Spatial variability in sea surface temperature and wind-driven coastal upwelling along the southwest coast of India
}

\author{
Vivekanand Bharti*, J. Jayasankar, Phiros Shah, S. P. Shukla', Grinson George and \\ T. V. Sathianandan \\ ICAR-Central Marine Fisheries Research Institute, Kochi - 682 018, Kerala, India. \\ 'ICAR-Central Institute of Fisheries Education, Mumbai - 400 061, Maharashtra, India. \\ *Correspondence e-mail: vivekanandbharti15@gmail.com
}

Received: 15 Sep 2018 Accepted: 13 Aug 2019 Published: 10 Sep 2019

Original Article

\begin{abstract}
The coastal environment along the southwest coast of India is influenced by seasonal wind-driven coastal upwelling. The trend of upwelling index (UI) and sea surface temperature (SST) along the southwest coast of India during 1988-2015 were analysed in this study. In order to understand the spatial variation in SST and UI, the entire southwest coast of India was divided into three strata viz. stratum_1 (ST_1, southern part), stratum 2 (ST 2, middle part) and stratum 3 (ST 3, northern part). Temporal analyses of these parameters were carried out for three seasons such as monsoon (June-September), post-monsoon (OctoberJanuary) and pre-monsoon (February-May). In addition to seasonal changes in upwelling, large-scale latitudinal differences in upwelling were observed during this study, which is associated with spatial differences in coastal topography. The upwelling index along stratum_3 has increased after 1995 compared to previous period. Both SST and UI exhibited spatial variation along southwest coast of India. Eventhough, $\mathrm{Ul}$ is higher during the summer monsoon compared to other seasons, a declining trend in $\mathrm{UI}$ during the summer monsoon was found from 1988 to 2015.
\end{abstract}

Keywords: Upwelling index, SST, southwest coast of India, stratum, monsoon

\section{Introduction}

About $71 \%$ of the world's coastlines have been significantly warming with highly heterogeneous rates of change in both spatial and season scale. Upwelling systems are one of the most important spots of productivity, it is also necessary to analyse in detail the evolution of SST patterns over these areas (Varela et al., 2016). Coastal upwelling may be defined as offshore transport of coastal surface water and its replacement by cold, nutrient-rich subsurface water, stimulating primary productivity (Hickey and Banas, 2008; Muni Krishna, 2008; Engida et al., 2016). Seasonal coastal upwelling appears in the response of the coastal ocean to alongshore winds, leading to the production of a relatively intense current with a small offshore and a large alongshore component, which causes the pumping of cooler and nutrient-rich subsurface water from 50-150 m depth to the ocean surface (Narayan et al., 2010). The southwest coast of India between $8^{\circ} \mathrm{N}$ and $16^{\circ} \mathrm{N}$ is an important productive region due to the existence of coastal upwelling (Muni Krishna, 2008; Smitha et al., 2008; Smitha et al., 2014; Gireeshkumar et al., 2017). In this region, upwelling is a wind-driven process and the strength of alongshore winds stress modulates the coastal divergence and hence the input of cold upwelled water over the shelf (Muni Krishna, 2008). Sea surface wind is an important driving force for the coastal 
upwelling, which describes wind-induced divergence caused by Ekman transport (Bakun et al., 1998; Smitha et al., 2008). A unique wind-forcing pattern occurs over the Indian Ocean, unlike the pattern over the other oceans, where northerly winds blow strongly during the southwest monsoon (June-September) along the southwest coast of India and the winds are very weak during the post-monsoon (October-January) and pre-monsoon (February-May). Northerly wind along the west coast of India drives an offshore Ekman transport together with a surface flow parallel to the coast (Smitha et al., 2008). Based on these wind patterns, Ekman theory predicts coastal upwelling phenomenon (Engida et al., 2016).

Due to the ecological and economic importance of upwelling system, changes in upwelling strength over time have attracted considerable scientific interest in recent decades. Several researchers have documented the trends in wind strength due to climate variability and the resultant changes in the coastal upwelling process worldwide. But, a limited study has been conducted so far on the influence of rising SST on wind-driven upwelling along the southwest coast of India. Therefore, the aim of this paper was to analyse SST trends along the southwest coast of India and its relation with coastal upwelling during the two decades of strong climate change.

\section{Material and methods}

\section{Study area}

Southwest coast of India between $8^{\circ}$ to $16^{\circ} \mathrm{N}$ latitude and $73^{\circ}$ to $77^{\circ} \mathrm{E}$ longitude, up to $100 \mathrm{~m}$ depth was selected for the study. This coastal area is known as upwelling zone, which makes it the most productive amongst all other regions of Indian EEZ including offshore and inshore waters. To assess

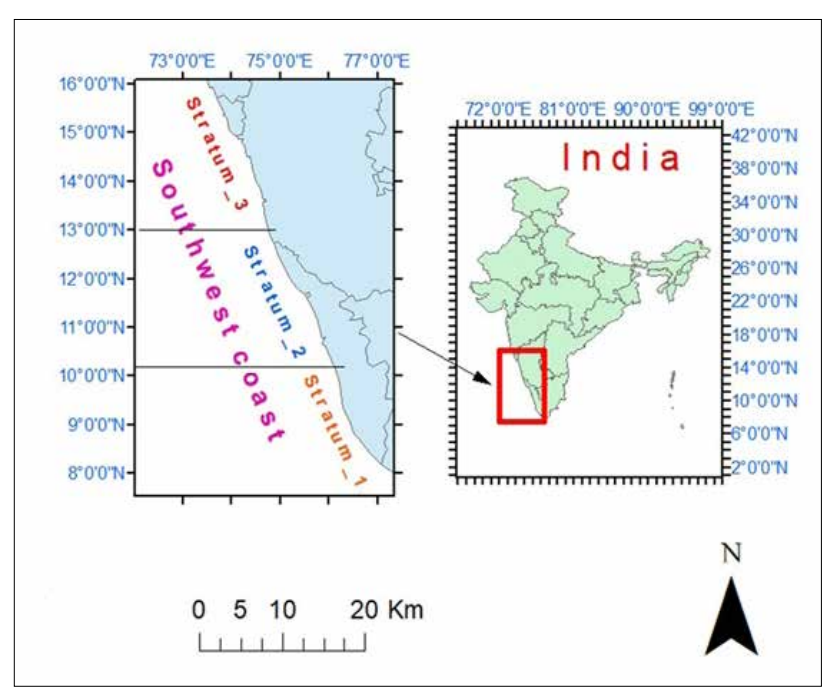

Fig.1. Map of southwest coast of India with strata the spatial upwelling index, the entire southwest coast of India has been classified into three latitudinal strata viz. stratum_1 $\left(8-10.2^{\circ} \mathrm{N}\right.$, southern part), stratum_2 (10.2-13 $\mathrm{N}$, middle part) and stratum_3 (13-16 $6^{\circ} \mathrm{N}$, northern part), as shown in Fig. 1.

\section{Data collection}

Shore-parallel wind stress has an important role in Ekmandriven upwelling. Monthly wind data was collected separately as zonal (U component) and meridional ( $V$ component) components at a vertical layer $10 \mathrm{~m}$ above sea surface for the period of 1988-2015 and at a spatial resolution of 0.25 degree grid from Cross-Calibrated Multi-Platform (CCMP) Ocean Vector Wind Analysis (V2.0) from Asia Pacific Data Research Centre website (http://apdrc.soest.hawaii.edu). SST was retrieved at a spatial resolution of $1^{\circ} \times 1^{\circ}$ during 19882015 on monthly basis from NOAA Optimum Interpolation (OI) SST, V2 from Asia Pacific Data Research Centre website (http://apdrc.soest.hawaii.edu). Monthly data on both SST and wind were collected for $8^{\circ}$ to $16^{\circ} \mathrm{N}$ latitude and $73^{\circ}$ to $77^{\circ} \mathrm{E}$ longitude. NOAA - bathymetric maps in R (library Marmap) were used to partition data for depth up to 100 $\mathrm{m}$. Up to $100 \mathrm{~m}$ of the continental shelf along the southwest coast of India shows high primary productivity, which limits the major fishing activities within this depth (Core Team, 2013; Pante and Bouhet, 2015). The partitioned data was again segregated at stratum level in R3.4.4 software for Windows. The collected monthly data again grouped into three seasons viz. pre-monsoon (February-May), monsoon (June-September) and post-monsoon (October-January) for analysis of seasonal variation.

\section{Upwelling index calculation}

Ekman transport derived (Q) from the alongshore wind stress was taken for the study of coastal upwelling index (UI). Under this postulation, $\mathrm{UI}$ is defined as $-\mathrm{Q}\left(\mathrm{m}^{3} \cdot \mathrm{s}^{-1} \cdot \mathrm{km}^{-1}\right)$, which is the volume transported per distance unit of an alongshore section. The sign of Ekman transport is changed to define positive or negative values of UI as a response of upwelling or downwelling depending on facilitating wind patterns (Gonzalez-Nuevo et al., 2014). Along the southwest coast of India, the alongshore components $\left(V_{y}\right)$ and cross-shore components $\left(U_{x}\right)$ of wind were computed as follows (Shah et al., 2015):

$\mathrm{V}_{\mathrm{y}}=\mathrm{V} \cos \Phi-\mathrm{U} \sin \Phi$

$\mathrm{U}_{\mathrm{x}}=\mathrm{U} \cos \Phi+\mathrm{V} \sin \Phi$

Where, $\mathrm{U}$ and $\mathrm{V}$ are zonal, and meridional components of wind, respectively, and $\varnothing$ is the inclination of the coast (Table1). 
Vivekanand Bharti et al.

Table 1. Inclination range (with respect to true north) along the southwest coast of India

\begin{tabular}{llll}
\hline Latitude $\left({ }^{\circ} \mathrm{N}\right)$ & Inclination $\left(^{\circ}\right)$ & Latitude $\left({ }^{\circ} \mathrm{N}\right)$ & Inclination $\left(^{\circ}\right)$ \\
\hline $8-9$ & 35 & $12-13$ & 22 \\
\hline $9-10$ & 18 & $13-14$ & 14 \\
\hline $10-11$ & 24 & $14-15$ & 28 \\
\hline $11-12$ & 30 & $15-16$ & 30
\end{tabular}

Shah et al., 2015

The alongshore components $\left(\mathrm{V}_{\mathrm{y}}\right)$ and cross-shore components $\left(U_{x}\right)$ of wind were used to calculate the magnitude of wind speed (W) as given:

To estimate Ekman transport (Q), at first converted monthly wind components to wind stress $\left(\tau_{y}\right)$ using the equation (Smitha et al., 2008):

$\tau_{y}=\rho a \cdot C d \cdot W \cdot V y$

Where, constant air density $\left(\rho_{\mathrm{a}}\right)=1.22 \mathrm{~kg} \mathrm{~m}^{-3}$ and constant drag coefficient $\left(C_{d}\right)=0.0013$, alongshore components $\left(V_{y}\right)$ and magnitude of wind speed (W)

$\mathrm{W}=\sqrt{\mathrm{U}_{\mathrm{x}}^{2}+\mathrm{V}_{\mathrm{y}}{ }^{2}}$

Ekman transport $\left(\mathrm{Q}, \mathrm{m}^{3} \cdot \mathrm{s}^{-1} \cdot \mathrm{km}^{-1}\right)$ was calculated as follows (Gonzalez-Nuevo et al., 2014):

$\mathrm{Q}=\frac{\tau_{y}}{f \cdot \rho_{w}} \cdot 10^{3}$

Where, seawater density $\left(\rho_{\mathrm{w}}\right)=1025 \mathrm{~kg} \mathrm{~m}^{-3}$ and Coriolis parameter $(\mathrm{f})=2 \Omega \sin \theta, \Omega$ is the angular frequency of the earth $\left(7.29 \times 10^{-5}\right.$ radians per second $)$ at $\theta$ latitude.

\section{Data analysis}

All monthly data were converted as yearly data by using mean for all strata and the entire southwest coast of India. Again year-wise seasonal data was made by mean of four-month data i.e. mean of data from February to May for pre-monsoon season. Similarly, the mean of data from June to September and October to January were taken for deriving the seasonal data for monsoon and post-monsoon, respectively. The yearly data for all strata and season were used for plotting line graphs. Line graph was smoothed to visualize the trend with LOcally WEighted Scatter plot Smoother (LOWESS) function in R3.4.4 software for Windows. The LOWESS smoother uses locally-weighted polynomial regression (Ruckstuhl et al., 2001). The smoothed trend lines were compared among strata as well as seasons.

\section{Results and discussion}

\section{Sea Surface Temperature}

The trend of SST along the southwest coast of India had an upward slope during the study period. Again, upward trend of SST along the southwest coast of India may be classified into three-parts as (1) slow rising SST up to 1995, (2) intermediate rising SST during 1995 to 2005 and (3) faster rising SST from 2005 to 2015 . In the case of stratum wise study, a large difference in the SST between ST 1 and ST 2 was not found over the study period. But, a clear difference in SST between ST 2 and ST 3 was noticed in the result, where the lowest SST among all three strata was observed along ST_3. Changes in the location of the Sun have a direct effect on the intensity of solar radiation on the earth surface as seen in the result with the lowest SST at ST 3, which is situated at latitudinal northern region of the study area. Further, this result showed that the upward trend of SST along ST_3 was slower up to 2005, and afterward upward movement of SST became faster. Even though, the rising rate of SST along three strata may differ each other, the result indicated a continuous rising in SST along all strata, resulted in the highest SST during 2015 at all strata (Fig. 2). The continuous rising of SST in the result depicts the effect of global warming along the southwest coast of India.

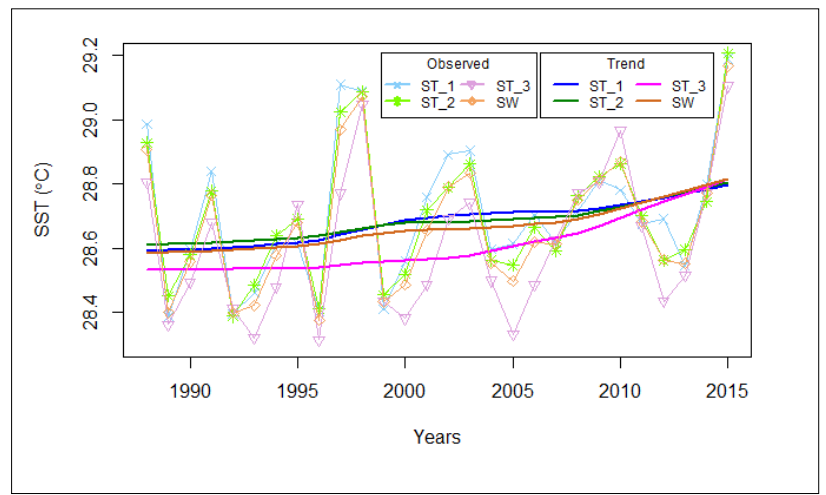

Fig. 2. Sea surface temperature variation along the strata and entire southwest coast of India, where ST_1 = stratum 1, ST $2=$ stratum_2, ST_3 = stratum_3 and SW = southwest coast of India

In the seasonal study of SST, a clear difference in SST was observed among all three seasons, where the highest and lowest SST were recorded during pre-monsoon and monsoon respectively. The rising trend of SST during both pre-monsoon and post-monsoon may be found after 1995. But, in the case of monsoon season which is the 
coolest season in the result, rising in SST was noticed after 2005 (Fig. 3). However, this result demonstrated that the trend of SST along the southwest coast of India started to increase after 1995, but the rising trend of SST might have accelerated after 2005. The faster growth in development and industrialization activities during 90 's decade might have resulted the rapid rise in global greenhouse gas sharing of India after 1990 onwards, therefore, showing an upward trend of SST after 1995 (Sathaye et al., 2006). The strength of upwelling along southwest coast of India has been facing the major alteration under the influence of rapid rising in SST since 90's decade (Jayaram et al., 2010).

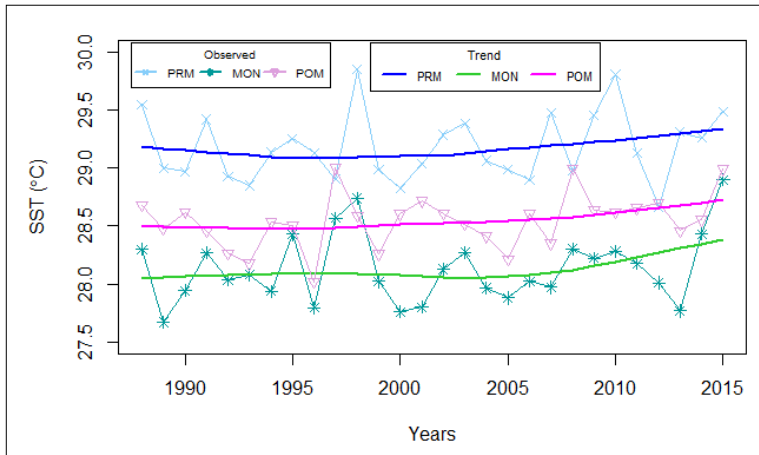

Fig. 3. Seasonal sea surface temperature variation along southwest coast of India, where PRM = pre-monsoon, $\mathrm{MON}=$ monsoon and $\mathrm{POM}=$ post-monsoon.

\section{Upwelling index}

The result of $\mathrm{UI}$ in this study indicated that the highest $\mathrm{UI}$ was at ST_1 in comparison to other strata. The UI decreased from south to northern region, resulted in the lowest UI at ST_3 (Fig. 4). UI trend at ST_1 was decreased continuously over the study period. However, UI along both ST_2 and ST_ 3 are much lower than that of ST_1, and the result showed a similar decreasing pattern of UI along both ST_2 and ST_3 with lowest local point during 1996. Similarly, the delineation of UI by Jayaram et al. (2010) showed higher values between $8^{\circ}$ and $9^{\circ} \mathrm{N}$ during summer monsoon. This result is also supported by the finding as the coastal upwelling along off Kochi remains its peak during July, but further, its intensity reduces towards north (Rao et al., 2008). Higher SST may not be favourable for $\mathrm{Ul}$, which is found in this study. Along with an increase of SST, a decreasing trend of UI was recorded at all the strata. In the case of seasonal study the $\mathrm{UI}$ was found to be high during monsoon season, which is the coolest season along the southwest of India (Fig. 5). However, only the temperature gradient over spatially and temporally may not give a clear idea about the distribution of $\mathrm{UI}$ along the southwest coast of India. The topographical condition at the southwest coast of India may also have to be considered to understand the $\mathrm{UI}$

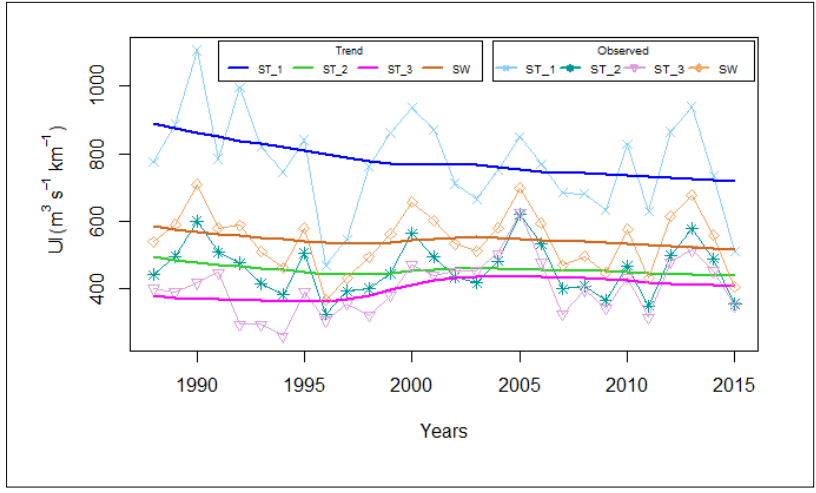

Fig. 4. Upwelling index variation along the strata and entire southwest coast of India, where ST_1 = stratum_1, ST 2 = stratum_2, ST_3 = stratum_3 and SW = southwest coast of India

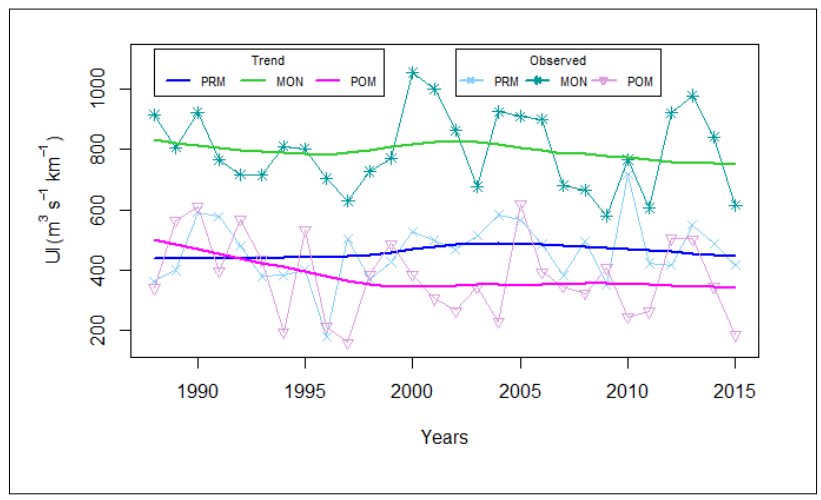

Fig. 5. Seasonal upwelling index variation along southwest coast of India, where PRM = pre-monsoon, $\mathrm{MON}=$ monsoon and POM = post-monsoon

pattern. A well-known difference in topography of southwest coast of India exist where western ghats runs parallel and continuously except at a $30-\mathrm{km}$ wide Palghat gap at $11^{\circ} \mathrm{N}$ which may affect the wind blow, other than narrowing of continental shelf from northern to the southern region. Jayaram et al. (2010) stated, an intra-regional variability along the southwest coast as the reason for the observation of the maximum upwelling at $8^{\circ}$ to $9^{\circ} \mathrm{N}$. Similar to finding of the present study as latitudinal difference in upwelling along the southwest coast of India was also observed by Smitha et al. (2008), where upwelling was weak at the northern part of the southwest coast of India between $13^{\circ} \mathrm{N}$ to $15^{\circ} \mathrm{N}$, due to weak wind stress at this coastal belt.

During the period of 1995 to 2005, UI along ST_3 showed an increasing trend, therefore, the differences for $U$ U between ST_2 and ST_3 had reduced after 2005. The change in wind pattern under the impact of global warming might have taken place at ST_3, where large continental shelf area is found, and therefore, an increased trend of UI at ST_ 3 might have seen for a shorter period. The result followed the hypothesis of Bakun (1990) on coastal upwelling under climate change scenario as 
global warming with increased concentrations of greenhouse gases would enhance warm-season upwelling. But, the Bakun (1990) hypothesis of strengthening of upwelling-favourable winds under global warming condition may be appropriate for lower depth as below $50 \mathrm{~m}$ water area. At higher depth water area such as $100 \mathrm{~m}$, the warming of the ocean has long been linked to greater stratification of the thermocline (Roemmich and McGowan, 1995). As higher warming takes place near surface water column, which enhances the ocean stratification, resulted in the decline of UI (Oyarzún and Brierley, 2019). Therefore, thermal stratification might be the reason for sharp declining of UI at ST_1, where narrow continental shelf is present.

This finding also explain that the lowering of seasonal SST is associated with an increase in UI, which is actually noticeable only with the onset of southwest monsoon (Smitha et al., 2008). The strong northerly winds were responsible for the highest upwelling during monsoon season along the southwest coast of India. The rising of SST due to climate change may be the reason for decline in $\mathrm{UI}$ along the southwest coast, which was observed during pre-monsoon and monsoon, the trend of UI decreased after 2005 when the temperature started to rise rapidly. It can be stated that the global warming along the southwest coast of India have a negative impact on $\mathrm{UI}$ and thus a reducing trend of UI was observed along the southwest coast of India. However, the driving mechanism for the prediction of coastal upwelling is still actively debated globally. But, this result supports the finding of Varela et al. (2016) as a small coastal warming during the upwelling season (July-October) is the driving force for a moderate decrease in UI along south coast of Java. Furthermore, consideration of the effect of the extreme event on $\mathrm{UI}$ is also required in the broader context in the comprehension of how climate change is influencing southwest of India. The result shows two lowest local peaks of UI at ST_1 during 1996 and 2015, where 1997 and 2015 are also considered as super strongest El Niño year in the history (Zhai et al., 2016).

It was found that $\mathrm{Ul}$ is unevenly distributed along the southwest coast of India, which decreased from the southern to northern region. UI of ST 2 and ST 3 were much lower than that of ST 1. Climate change due to global warming influences the upwelling system along the southwest coast of India. The present study reveals a preliminary understanding about the trend of SST and $\mathrm{UI}$ along the southwest coast of India and how these two parameters show spatial-temporal changes in the progression of time in the recent period under climate change. This baseline information on SST and UI may be useful in developing the socio-economic management strategies in this upwelled marine ecosystem in the southwest coast of India, which supports a large volume of pelagic fisheries for a long time.

\section{Acknowledgements}

The authors are grateful to the Director, ICAR-Central Marine Fisheries Research Institute, Kochi, India for providing all necessary facilities during this study. Authors would also like to thank Indian Council of Agricultural Research, New Delhi, India for the financial support. The first author also wishes to express his gratitude to the research advisory committee for their fruitful inputs in partial fulfilment of PhD.

\section{References}

Bakun, A. 1990. Global climate change and intensification of coastal ocean upwelling. Science, 247: 198-201.

Bakun, A., C. Roy and S. Lluch-Cota. 1998. Coastal upwelling and other processes regulating ecosystem productivity and fish production in the western Indian Ocean. In: K. Sherman, E. N. Okemwa and M. J. Ntiba (Eds.), Large Marine Ecosystems of the Indian Ocean: Assessment, Sustainability and Management. Cambridge, Massachusetts, Blackwell Science, p. 103-141.

Core Team. 2013. R: A language and environment for statistical computing. R Foundation for Statistical Computing, Vienna, Austria. URL http://www.R-project.org.

Engida, Z., A. Monahan, D. lanson and R. E. Thomson. 2016. Remote forcing of subsurface currents and temperatures near the northern limit of the California Current System. J. Geophys. Res. Oceans., 121: 7244-7262.

Gireeshkumar, T. R. D. Mathew, A. K. Pratihary, H. Naik, K. U. Narvekar, J. Araujo, K. K. Balachandran, K. R. Muraleedharan, B. Thorat, M. Nair and S. W. A. Naqvi. 2017. Influence of upwelling induced near shore hypoxia on the Alappuzha mud banks, Southwest Coast of India. Cont. Shelf. Res., 139: 1-8.

Gonzalez-Nuevo, G., J. Gago and J. M. Cabanas. 2014. Upwelling index: a powerful tool for marine research in the NW Iberian upwelling system. J. Oper. Oceanogr., 7(1): 47-57.

Hickey, B. and N. Banas. 2008. Why is the northern end of the California Current System so productive? Oceanography, 21(4): 90-107.

Jayaram, C., N. Chacko, K. A. Joseph and A. N. Balchand. 2010. Interannual variability of upwelling indices in the southeastern Arabian Sea: A satellite based study. Ocean Sci. J., 45(1): 27-40.

Muni Krishna. 2008. Coastal upwelling along the southwest coast of India - ENSO modulation. Ann. Geophys., 26: 1331-1334.

Narayan, N., A. Paul, S. Mulitza and M. Schulz. 2010. Trends in coastal upwelling intensity during the late 20th century. Ocean. Sci., 6: 815-823.

Oyarzún, D. and C. M. Brierley. 2019. The future of coastal upwelling in the Humboldt current from model projections. Clim. Dynam., 52 (1-2): 599-615.

Pante, E. and B. S. Bouhet. 2015. Making and using bathymetric maps in R with marmap, P. 1-12

Rao, A. D., M. Joshi and M. Ravichandran. 2008. Oceanic upwelling and downwelling processes in waters off the west coast of India. Ocean. Dyn. 58: 213-226.

Roemmich, D. and J. McGowan. 1995. Climatic warming and the decline of Zooplankton in the California Current. Science, 267(5202): 1324-1326.

Ruckstuhl, A. F., M. P. Jacobson, R. W. Field and J. A. Dodd. 2001. Baseline subtraction using robust local regression estimation. J. Quant. Spectrosc. Ra., 68: 179-193.

Sathaye, J., P. R. Shukla and N. H. Ravindranath. 2006. Climate change, sustainable development and India: Global and national concerns. Curr. Sci. India, 90 (3): 314-325.

Shah, P., R. Sajeev and N. Gopika. 2015. Study of Upwelling along the West Coast of India - A Climatological Approach. J. Coastal. Res., 31(5): 1151-1158.

Smitha, A., K. A. Joseph, C. Jayaram and A. N. Balachand. 2014. Upwelling in the southeastern Arabian Sea as evidenced by Ekman Mass transport using wind observation from OCEANSAT-II Scatterometer, Indian J. Geo-Mar. Sci., 43: 111-116.

Smitha, B. R., V. N. Sanjeevan, K. G. Vimal Kumar and C. Revichandran. 2008. On the Upwelling off the Southern Tip and along the West Coast of India. J. Coastal. Res., 24 (4C): 95-102

Varela, R, F. Santos, M. Gómez-Gesteira, I. Álvarez, X. Costoya, J. M. Días. 2016. Influence of Coastal Upwelling on SST Trends along the South Coast of Java. PLoS ONE 11(9): e0162122.

Zhai, P., Y. Ron, G. Yanju, L. Qingxian, R. Xuejua, W. Yaqian, X. Wenhu, L. Yanj and D. Yih. 2016. The Strong El Nino of 2015/16 and Its Dominant Impacts on Global and China's Climate. J. Meteorol. Res. 30 (3): 283-297. 